\title{
Novel use of a cardiac septal occluder to treat a chronic recalcitrant bariatric fistula after Roux-en-Y gastric bypass
}

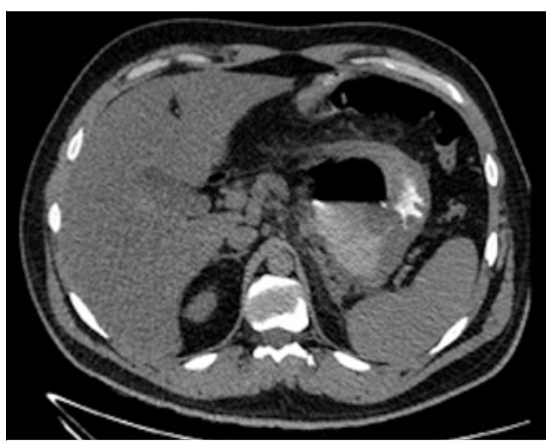

Fig. 1 Computed tomography with evidence of free fluid and abdominal collection.

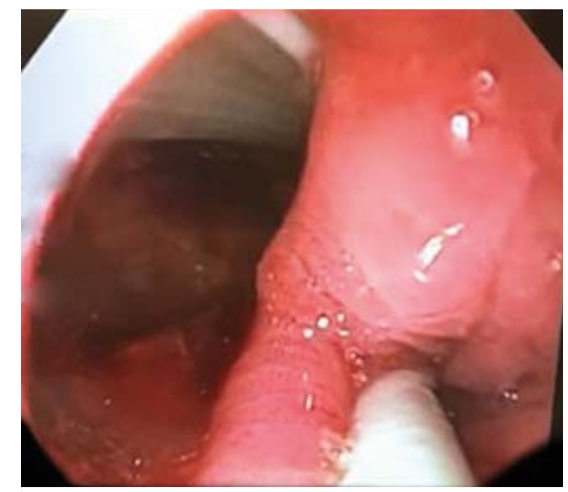

Fig. 2 Endoscopic view of the fistulous orifice.

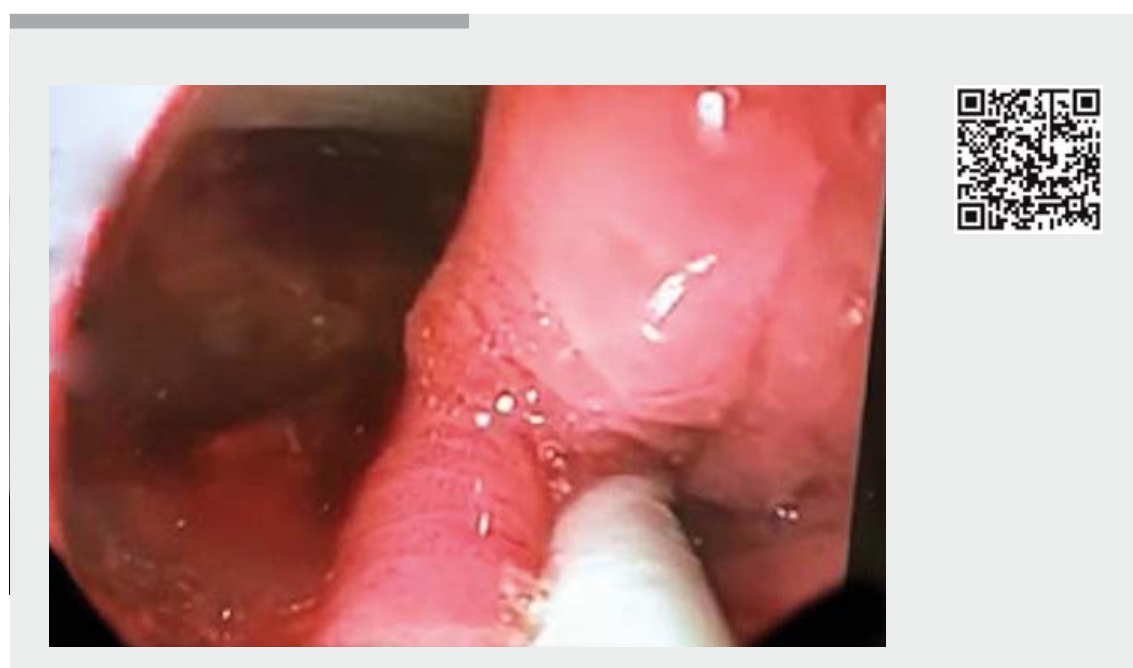

Video 1 Off-label use of the cardiac septal occluder (AMPLATZER Septal Occluder; Abbott, St. Paul, Minnesota, USA) for the treatment of chronic fistula after bariatric surgery with Roux-en-Y gastric bypass. After 15 days, the cutaneous ostium was closed completely. The patient remained asymptomatic at the 3-month follow-up. The cardiac septal occluder device appears to be effective and safe in the treatment of chronic bariatric fistulas. It seems to be an option mainly after conventional therapies have failed.

Although considered the gold standard for the treatment of obesity, bariatric surgeries are not free of complications. Fistulas occur after Roux-en-Y gastric bypass (RYGB) and sleeve gastrectomy in up to $8.3 \%$ and $7 \%$ of patients, respectively $[1,2]$. We describe the first report of the off-label use of the cardiac septal occluder (AMPLATZER Septal Occluder;
Abbott, St. Paul, Minnesota, USA) for the treatment of a chronic bariatric fistula ( $\triangleright$ Video 1$)$.

A 33-year-old man with grade II obesity underwent RYGB. After 1 week, the patient was admitted with abdominal pain and fever. Computed tomography scan diagnosed a gastric pouch leak associated with intra-abdominal collec-

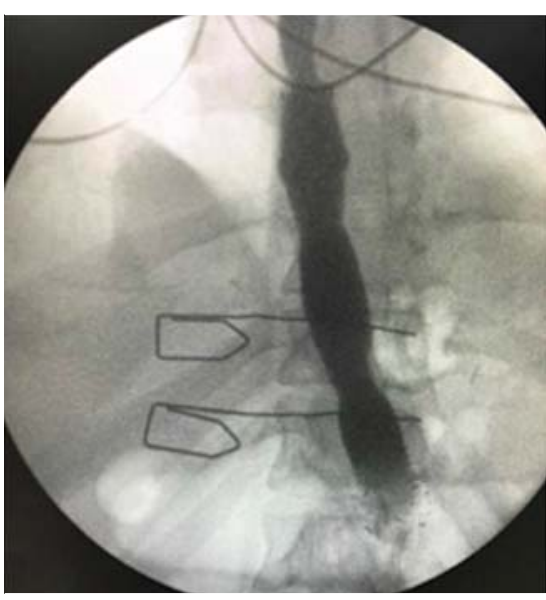

- Fig. 3 Radiological image demonstrating absence of contrast leakage after placement of a fully covered self-expandable metal stent. The first (proximal) clip indicates the fistulous orifice and the second indicates the gastrojejunal (distal) anastomosis.

tions ( $\triangleright$ Fig. 1). Emergency surgery was indicated, a peri-gastric collection associated with a gastric pouch leak was confirmed, and placement of two abdominal drains was performed, followed by admission to the intensive care unit.

After 25 days, the drain output was $300 \mathrm{~mL} /$ day, and an upper endoscopy showed a $20-\mathrm{mm}$ leak in the gastric pouch in the topography of the superior staple line, just below the esophagogastric junction ( $>$ Fig.2). An esophageal fully covered metal stent (Hanaro, $16 \mathrm{~cm} \times 22 \mathrm{~mm}$; Micro Tech Co. Ltd., Anseong-Si, South Korea) was placed ( $\triangleright$ Fig.3). The stent was fixed with the Shin technique to avoid migration [3]. After the stent placement, the drain output decreased to $30 \mathrm{~mL} /$ day. The stent was removed 4 weeks later because of patient intolerance. During the endoscopy, a chronic fistula $(15 \mathrm{~mm})$ with the external drain tube inside the orifice was observed. The drain was removed under direct endoscopic vision, until the endoscope was advanced to 

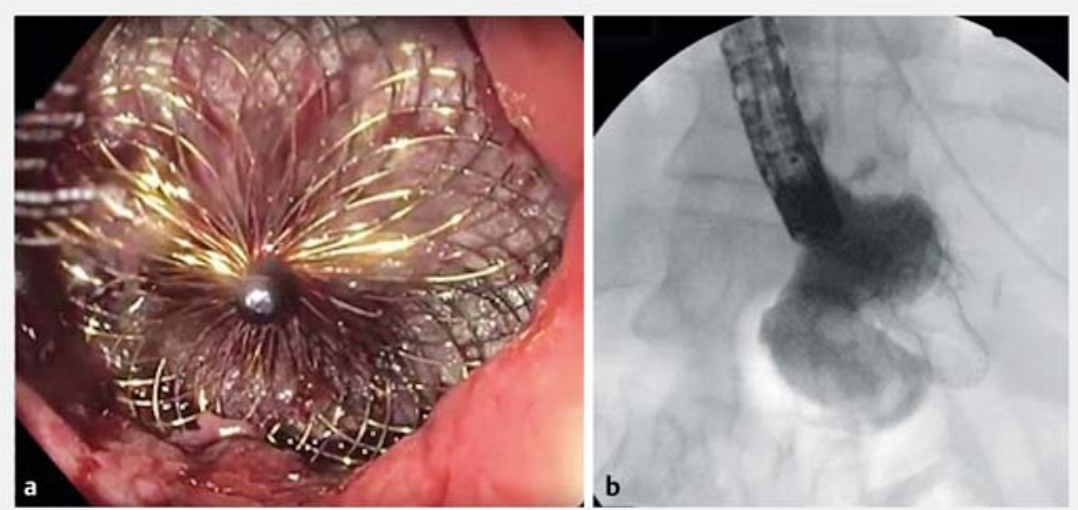

- Fig. 4 The septal cardiac occlude. a Endoscopic view. b Fluoroscopic view.

the skin. The fistula tract was noted to be fully epithelized.

As this chronic fistula remained unresponsive, placement of a cardiac septal occluder was performed ( $\downarrow$ Video 1 , - Fig. 4) [4, 5].

After 15 days, the cutaneous ostium was closed completely ( $>$ Fig.5). The patient remained asymptomatic at the 3-month follow-up.

Endoscopy_UCTN_Code_TTT_1AO_2AI

\section{Competing interests}

Dr. Thompson reports personal fees from Boston Scientific, personal fees from Olympus, outside the submitted work.

\section{The authors}

Diogo Turiani Hourneaux de Moura ${ }^{1,2}$, Igor Braga Ribeiro ${ }^{1}$, Mateus Pereira Funari ${ }^{1}$, Alberto Baptista ${ }^{3}$, Christopher C. Thompson², Eduardo Guimarães Hourneaux de Moura' ${ }^{1}$

1 Gastrointestinal Endoscopy Unit, Hospital das Clínicas da Faculdade de Medicina da Universidade de São Paulo, São Paulo, Brazil

2 Division of Gastroenterology, Harvard Medical School, Brigham and Women's Hospital, Boston, Massachusetts, United States

3 Department of Endoscopy, Hospital de Clinicas Caracas, San Bernardino, Venezuela
Corresponding author

\section{Igor Braga Ribeiro, MD}

Gastrointestinal Endoscopy Unit, Hospital das Clínicas da Faculdade de Medicina da Universidade de São Paulo, Av. Dr Enéas de Carvalho Aguiar, 225, $6^{\circ}$ andar, bloco 3 , Cerqueira Cesar 05403-010, São Paulo, Brazil Fax: +55-11-26616467

igorbraga1@gmail.com

\section{References}

[1] Ribeiro IB, Gestic MA, Utrini MP et al. Drain amylase levels may indicate gastrojejunostomy leaks after Roux-en-Y gastric bypass. Arq Gastroenterol 2018; 55: 66-72

[2] Okazaki O, Bernardo WM, Brunaldi VO et al. Efficacy and safety of stents in the treatment of fistula after bariatric surgery: a systematic review and meta-analysis. Obes Surg 2018; 28: $1788-1796$

[3] Martins BC, Retes FA, Medrado BF et al. Endoscopic management and prevention of migrated esophageal stents. World J Gastrointest Endosc 2014; 6: 49-54

[4] Repici A, Presbitero P, Carlino A et al. First human case of esophagus-tracheal fistula closure by using a cardiac septal occluder (with video). Gastrointest Endosc 2010; 71 : $867-869$

[5] Melmed GY, Kar S, Geft I et al. A new method for endoscopic closure of gastrocolonic fistula: novel application of a cardiac septal defect closure device (with video). Gastrointest Endosc 2009; 70: 542 - 845

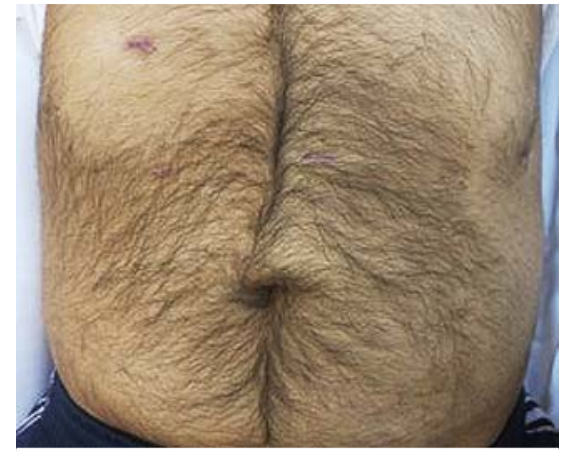

- Fig. 5 Abdominal wall with complete closure of the two holes of the abdominal drains.

\section{Bibliography}

DOI https://doi.org/10.1055/a-0842-6287

Published online: 21.2.2019

Endoscopy 2019; 51: E111-E112

(c) Georg Thieme Verlag KG

Stuttgart · New York

ISSN 0013-726X

\section{ENDOSCOPY E-VIDEOS \\ https:/|eref.thieme.de/e-videos}

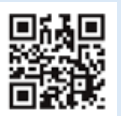

Endoscopy E-Videos is a free access online section, reporting on interesting cases and new techniques in gastroenterological endoscopy. All papers include a high quality video and all contributions are freely accessible online.

This section has its own submission website at https://mc.manuscriptcentral.com/e-videos 